\title{
Properties of Ceramic Substrate Materials for High-Temperature Pressure Sensors for Operation above $1000^{\circ} \mathrm{C}$
}

\author{
YanJie Guo $\mathbb{D}^{1,2}$ Fei Lu, ${ }^{1,2}$ Lei Zhang, ${ }^{1,2}$ HeLei Dong, ${ }^{1,2}$ QiuLin Tan $\mathbb{D}^{1,2}$ and JiJun Xiong ${ }^{1,2}$ \\ ${ }^{1}$ Key Laboratory of Instrumentation Science and Dynamic Measurement, Ministry of Education, North University of China, \\ Tai Yuan 030051, China \\ ${ }^{2}$ Science and Technology on Electronic Test and Measurement Laboratory, North University of China, Tai Yuan 030051, China
}

Correspondence should be addressed to QiuLin Tan; tanqiulin@nuc.edu.cn

Received 15 January 2018; Accepted 15 March 2018; Published 3 April 2018

Academic Editor: Marco Cannas

Copyright (C) 2018 YanJie Guo et al. This is an open access article distributed under the Creative Commons Attribution License, which permits unrestricted use, distribution, and reproduction in any medium, provided the original work is properly cited.

In order to identify suitable substrate materials for sue in high-temperature pressure sensors that can operate above $1000^{\circ} \mathrm{C}$, the high-temperature properties of four high-performance ceramics (99\% pure $\mathrm{Al}_{2} \mathrm{O}_{3}\left(99 \mathrm{Al}_{2} \mathrm{O}_{3}\right), 97 \%$ pure $\mathrm{Al}_{2} \mathrm{O}_{3}\left(97 \mathrm{Al}_{2} \mathrm{O}_{3}\right)$, sapphire, and $\mathrm{ZrO}_{2}$ ) were investigated. Three-point bend testing was used to measure the flexural strengths and flexural moduli of these ceramics, and transient laser emission was used to measure their thermal conductivities. The samples were prepared by hotpress sintering: plates with the dimensions of $3.5 \times 5 \times 50 \mathrm{~mm}^{3}$ for the bend testing and rods of $\varphi 12.5 \times 1.5 \mathrm{~mm}^{3}$ for the thermal conductivity measurements. Curves showing the dependence of flexural strength, flexural modulus, and thermal conductivity on temperature were obtained. The results show that the flexural strength and thermal conductivity of sapphire are much greater than those of the other ceramics tested. Thus, we conclude that sapphire is the most appropriate of these materials for use in hightemperature pressure sensors for operation at up to $1000^{\circ} \mathrm{C}$.

\section{Introduction}

Recently, high-temperature sensors have attracted much attention due to their excellent performance in harsh environments, such as high temperatures, high pressures, and corrosive atmospheres, and when subjected to strong mechanical shocks. For example, pressure monitoring in aircraft engines is of great importance for the correct functioning of aircraft. Currently, high-temperature pressure sensors that have been studied in-depth include silicon on insulator (SOI) high-temperature pressure sensors $[1,2]$, $\mathrm{SiC}$ high-temperature pressure sensors [3], silicon-sapphire pressure sensors [4], fiber optic pressure sensors [5], surface acoustic wave (SAW) pressure sensors [6], resonance circuit (LC circuit) pressure sensors [7-9], and microwavescattering resonance pressure sensors [10]. Among these high-temperature pressure sensors, the LC circuit pressure sensors based on high-temperature cofired ceramic (HTCC) alumina substrates can operate at temperatures above $800^{\circ} \mathrm{C}$. In the literature [11], ceramic-based temperature sensors have shown to operate above $1000^{\circ} \mathrm{C}$. By considering the various substrate materials of these high-temperature sensors, it can be concluded that the base materials of the hightemperature sensor must maintain stable performance in harsh environments. Four common high-temperature ceramics, $99 \mathrm{Al}_{2} \mathrm{O}_{3}, 97 \mathrm{Al}_{2} \mathrm{O}_{3}$, sapphire and $\mathrm{ZrO}_{2}$ have good oxidation and corrosion resistance, even in harsh environments. Since the materials processing technology for these ceramics is very mature, it is anticipated that it will be possible to use them to prepare high-temperature sensors that can operate above $1000^{\circ} \mathrm{C}$. Thus, we have chosen these four refractory ceramics for this study.

The mechanical and thermal properties of refractory ceramics are of great importance for their use as the substrate materials for high-temperature pressure sensors. Any variation in the temperature can significantly affect the sensor performance, particularly under contact conditions, where stress levels are especially high. There are several methods which can be used to assess mechanical properties. Three-point bend testing has been used to measure the 
strength of composite ceramics [11-14]; while the Hertz indentation test has been used to measure the stress-strain properties of alumina and zirconia ceramics [15]. For the Hertz indentation test, three conditions are required: firstly, the deformation of the contact surface should be low; secondly, the contact surface must be oval; and, thirdly, the contact objects should behave as elastic half-spaces. Only if all three of these conditions are satisfied, the measurements can be regarded as Hertz contacts and the test can be valid. For the three-point bend method, the loading is relativity simple and the required sample dimensions are also small; however, due to the highly localized loading, the sample does not experience uniform force. This may result in defects in some parts of the sample escaping detecting and affect the accuracy of the measurement. Since the samples in this study are relatively uniform and the defect distribution is homogeneous, the authors chose to use three-point bend testing to investigate the mechanical properties of the ceramics.

For the measurement of thermal properties (such as thermal conductivity), commonly used tests include steadystate methods and unsteady-state methods. Steady-state methods include the heat flow meter method and the hot plate method; unsteady-state methods include the hot wire method and transient laser emission method. Steady-state methods are limited to measuring longitudinal thermal conductivity, and the effective temperature ranges are limited. Additionally, these methods are primarily suited to low thermal conductivity materials and thermal insulation materials. In a previous paper [16], three methods for thermal conductivity measurement were presented, and each method had its own advantages and disadvantages. In another study [17], a transient short hot wire technique was developed for the simultaneous measurement of thermal conductivity and thermal diffusivity; the effects of the thermophysical properties and the size of the hot wire, insulation coating, and samples were investigated. In the hot wire method, it is necessary to insert the hot wire into the sample before testing, and a larger sample size is required. Taking into account that the Mohs hardness of these four kinds of ceramics is relatively large, this method is not very convenient to measure these ceramic samples in this study. Laser flash methods, such as transient laser emission, have been employed to measure the thermal properties of ceramics and metals and may also be suitable for measuring the thermal properties of polymers [18-21]. The advantage of laser flash methods is that the sample can be small, the detection speed is high, and the effective temperature range is wide. During the test, only the relative temperature is measured, obviating the need to calibrate the instrument for absolute temperature measurements. Because of these advantages, the authors chose the transient laser emission method to measure the thermal conductivity in this study.

By measuring the mechanical and thermal properties of high-temperature ceramics over a temperature range from $25^{\circ} \mathrm{C}$ to $1500^{\circ} \mathrm{C}$, we can assess their suitability for use in the preparation of sensor devices for ultra-high-temperature environments.

\section{Determination of the Test Parameters}

Owing to the operational mechanism of pressure sensors, the magnitude of the flexural modulus of the substrate directly affects the sensitivity of the pressure sensor. For resonant pressure sensors, when a given amount of pressure is applied to the surface of the sensor, a structure with a larger flexural modulus will produce a stronger signal. Further, the magnitude of the flexural strength determines the maximum measurement range of the sensor, and a pressure sensor with a lager flexural strength will be able to measure higher pressures.

Thermal conductivity is another important property of temperature-resistant materials; this is defined as the energy transferred per unit cross-sectional area per unit time when the vertical temperature gradient is $1^{\circ} \mathrm{C} / \mathrm{m}$. In high-temperature pressure sensors, the magnitude of the thermal conductivity directly affects the response time of the sensor and the accuracy of the measurement. The greater the thermal conductivity of the substrate, the smaller the temperature difference between the sensor and its environment, resulting in shorter response times and higher measurement accuracies.

\section{Test Principles and Equipment}

3.1. Flexural Test. In this study, three-point bend testing was used to measure the flexural strengths and moduli of the ceramics at different temperatures; this involves applying a load between two points of the sample until the sample is crushed. The measurements were carried out using WKM2200, which is developed by Ukraine Strength Research Institute, shown in Figure 1(a). The schematic of this system is shown in Figure 2(a). Using a tungsten-rhenium thermocouple and the heating wire, the temperature around the test specimen can be measured and controlled. The force applied to the specimen is adjusted via the motor, which is controlled by the motor driver and computer. The load applied to the specimen is recorded by the pressure sensor, and the loaddisplacement curves were recorded, as shown in Figure 2(b). The samples, namely, $99 \mathrm{Al}_{2} \mathrm{O}_{3}, 97 \mathrm{Al}_{2} \mathrm{O}_{3}$, sapphire, and $\mathrm{ZrO}_{2}$, with the dimensions of $3.5 \times 5 \times 50 \mathrm{~mm}^{3}$, prepared by hotpress sintering, are shown in Figure 3(a).

During the measurement, the temperature is raised to the measurement temperature and held for $10 \mathrm{~min}$ to stabilize. Then, the load is applied gradually so that the specimen undergoes bending deformation. In the initial deformation stage, the test sample will bend elastically. From the intercept of this linear region of the curve, and (1) and (2), the flexural modulus $E_{\mathrm{b}}$ of the sample can be obtained:

$$
\begin{gathered}
E_{\mathrm{b}}=\frac{L_{\mathrm{s}}^{3}}{48 I} \cdot \frac{\Delta F}{\Delta d}, \\
I=\frac{1}{12} \cdot\left(b h^{3}\right) .
\end{gathered}
$$

In (1) and (2), $L_{\mathrm{S}}$ is the span of the three-point bending test, which refers to the distance between two support points below the specimen; and $b$ and $h$ are the width and height of the specimens, respectively. The maximum bending force, $F_{\mathrm{b}}$ 


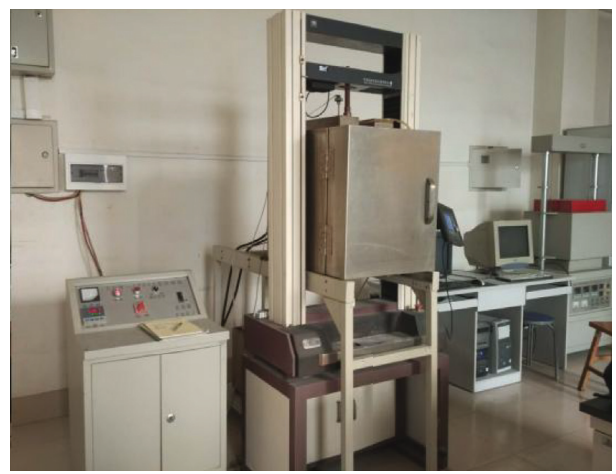

(a)

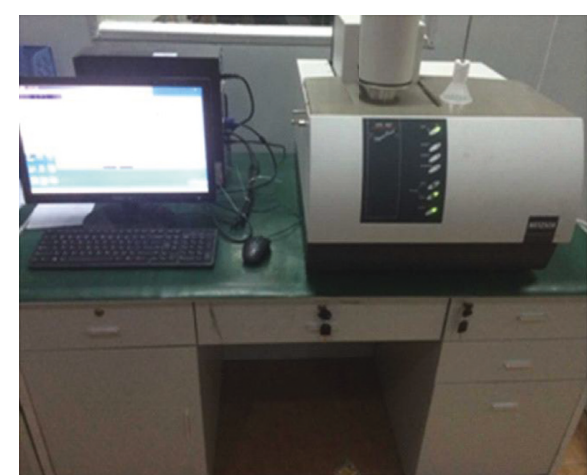

(b)

FIGURE 1: Photos of the test equipment: (a) WKM-2200 three-point bend testing device and (b) LFA-427 laser thermal conductivity meter.

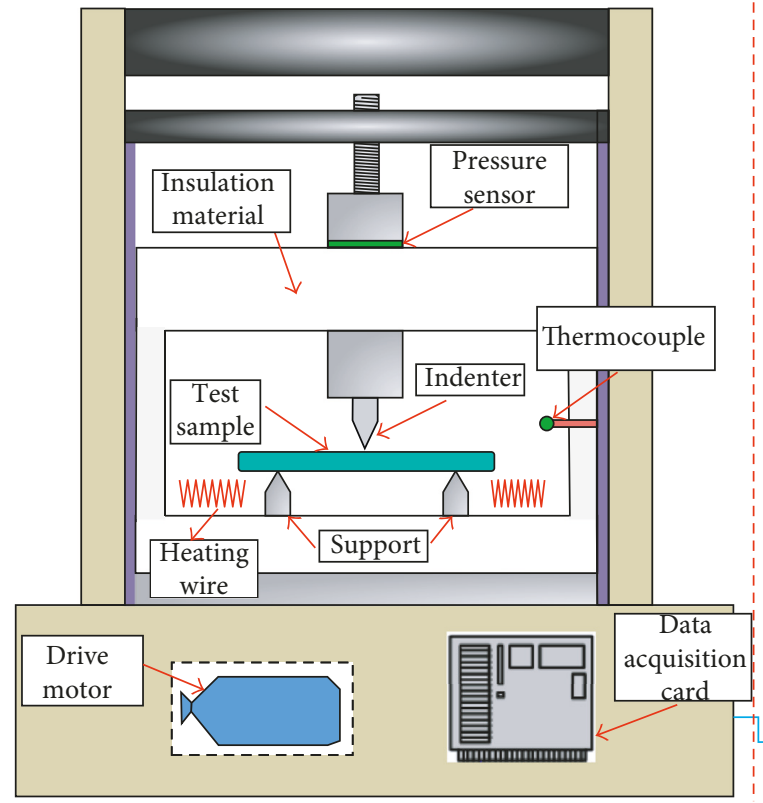

(a)

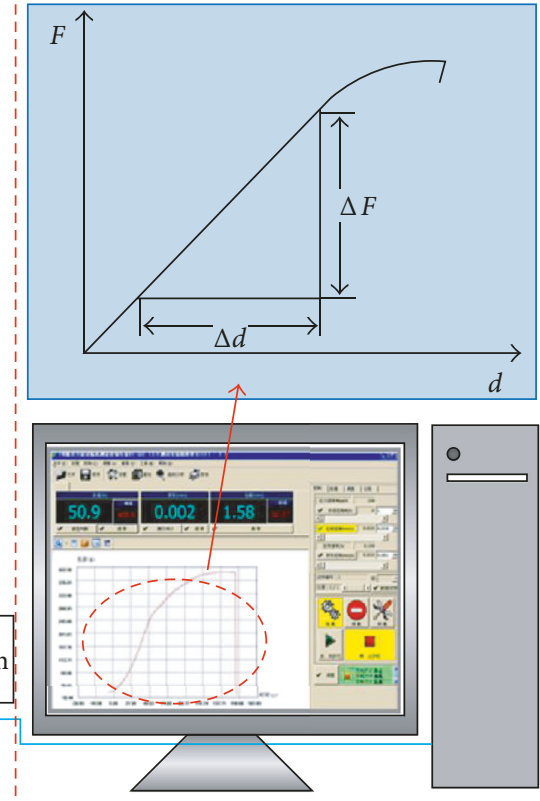

(b)

FIgure 2: The schematic of the flexural test system: (a) three-point bend test structure and (b) software processing section.

is extracted from the measured load-deflection curve; the bending strength $\sigma_{\mathrm{b}}$ can be calculated using the following equations:

$$
\begin{aligned}
& \sigma_{\mathrm{b}}=\frac{F_{\mathrm{b}} L_{\mathrm{s}}}{4 W}, \\
& W=\frac{1}{6} \cdot b h^{2} .
\end{aligned}
$$

3.2. Thermal Conductivity Test. For the thermal conductivity measurements, an LFA-427 (Netzsch) laser thermal conductivity meter were used, shown in Figure 1(b). The samples for the thermal conductivity measurements had the dimensions of $\varphi 12.5 \times 1.5 \mathrm{~mm}^{3}$ and were prepared by hotpress sintering, as shown in Figure 3(b). LFA-427 comprises a laser, a vacuum heating furnace, and temperature measurement, and data acquisition and processing units.
According to the definition of thermal conductivity, the relationship between thermal conductivity $k$, thermal diffusivity $\alpha$, specific heat capacity $C$, and material density $\rho$ can be expressed as

$$
k=\alpha \cdot C \cdot \rho .
$$

In order to obtain the thermal conductivity of the material, it is necessary to measure the thermal diffusivity $\alpha$ and specific heat capacity $C$ of the material. At a specified temperature, the sample is uniformly irradiated by a laser pulse, resulting in an instantaneous increase in the surface temperature. This surface serves as the hot end of the temperature gradient, and energy transfer to the cold end (upper surface) occurs via one-dimensional heat transfer. An infrared detector is used to measure the temperature of the upper surface. The half-temperature rise time $\left(t_{1 / 2}\right)$ when the temperature of the upper surface rises to half of the maximum value $T_{M}$ is recorded. The thermal diffusivity $\alpha$ can 


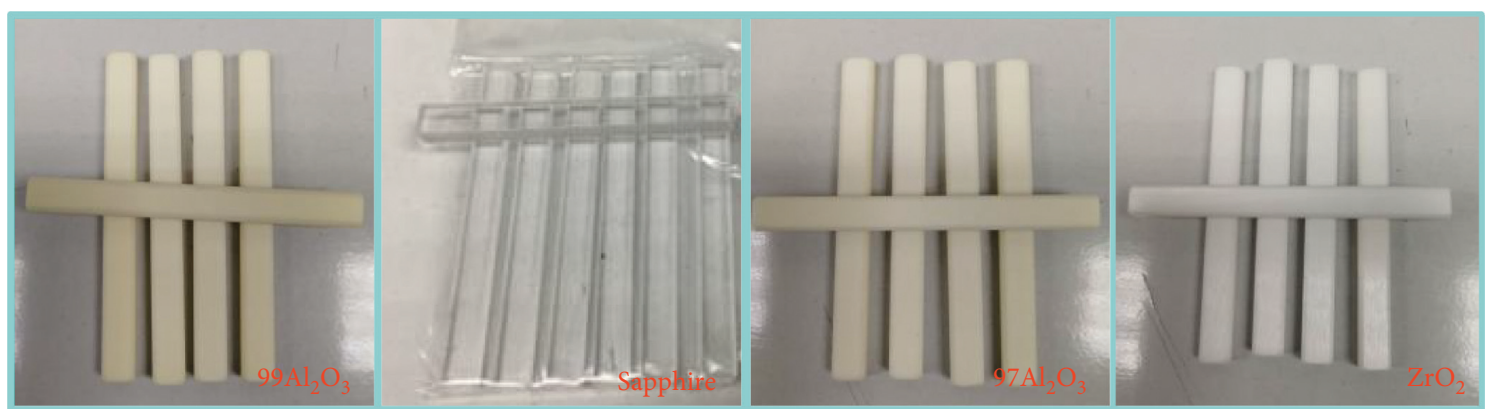

(a)

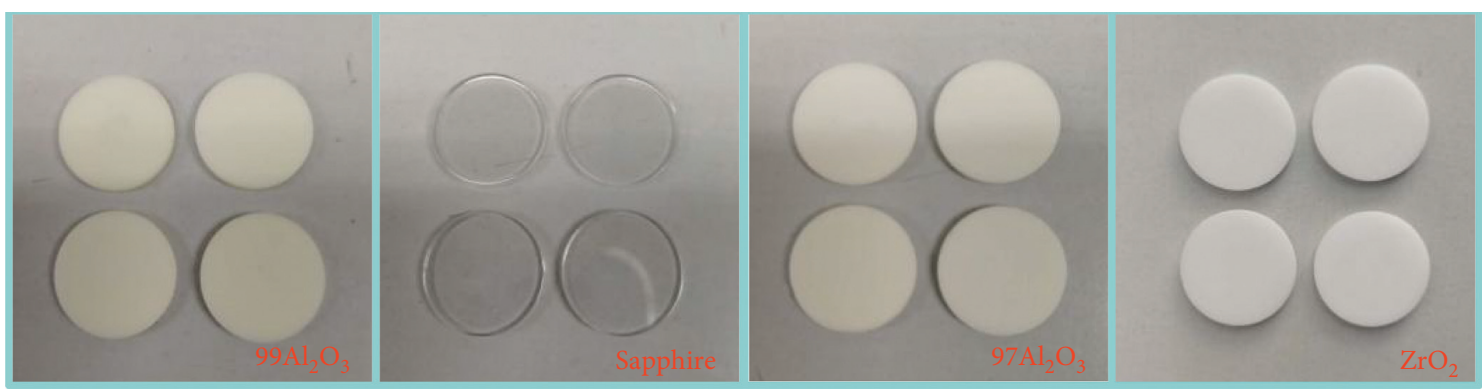

(b)

Figure 3: Test specimen: (a) size of $3.5 \times 5 \times 50 \mathrm{~mm}^{3}$ and (b) size of $\varphi 12.5 \times 1.5 \mathrm{~mm}^{3}$.

then be calculated using the following Fourier heat transfer equation:

$$
\alpha=1.38 L^{2} \cdot\left(\pi^{2} \cdot t_{1 / 2}\right)^{-1}
$$

To measure the specific heat capacity $C$ of the materials, a standard reference sample, with similar cross-sectional shape, thickness, thermal properties, surface roughness, and a known specific heat capacity $C_{(\text {std) }}$ is required. The reference sample and the test sample were subjected to surface coating at the same time. The definition of the specific heat capacity is shown in the following equation:

$$
C=Q \cdot(\Delta T \cdot m)^{-1},
$$

where $Q$ denotes the energy absorbed by the sample, $\Delta T$ denotes the temperature change after laser irradiation, and $m$ is the mass of the material. From this, it is possible to obtain the following equation:

$$
\frac{C_{\text {std }}}{C_{\text {sam }}}=\frac{Q_{\text {std }}}{\Delta T_{\text {std }} \cdot m_{\text {std }}} \cdot\left(\frac{Q_{\text {sam }}}{\Delta T_{\mathrm{sam}} \cdot m_{\text {sam }}}\right)^{-1},
$$

when the energy absorbed by the reference and test sample is the same, that is, $Q_{\text {std }}=Q_{\text {sam }}$, (8) can be replaced by the following equation:

$$
C_{\text {sam }}=C_{\text {std }} \cdot \Delta T_{\text {std }} \cdot m_{\text {std }} \cdot\left(\Delta T_{\text {sam }} \cdot m_{\text {sam }}\right)^{-1} .
$$

\section{Test Results and Analysis}

The flexural properties of $99 \mathrm{Al}_{2} \mathrm{O}_{3}, 97 \mathrm{Al}_{2} \mathrm{O}_{3}$, sapphire, and $\mathrm{ZrO}_{2}$ at $25^{\circ} \mathrm{C}, 800^{\circ} \mathrm{C}, 1200^{\circ} \mathrm{C}$, and $1500^{\circ} \mathrm{C}$ were measured using three-point bend testing, and load-displacement curves were obtained. Combining (1-4), the flexural strengths and flexural moduli of these ceramics at each temperature can be obtained. Plots of flexural strength and flexural modulus versus temperature are shown in Figures 4(a) and (b), respectively.

For the thermal conductivity measurements, graphite was selected as the standard reference sample. A temperature ramp of $20^{\circ} \mathrm{C} / \mathrm{min}$ from $25^{\circ} \mathrm{C}$ to $1500^{\circ} \mathrm{C}$ was used. The thermal diffusivity and specific heat capacity were measured directly, and (3) was used to calculate thermal conductivity; these results are shown in Figure 5.

As shown in Figure 4(a), the flexural strengths of sapphire and $\mathrm{ZrO}_{2}$ at $25^{\circ} \mathrm{C}$ are $740.8 \mathrm{MPa}$ and $603.1 \mathrm{MPa}$, respectively, while the flexural strengths of $99 \mathrm{Al}_{2} \mathrm{O}_{3}$ and $97 \mathrm{Al}_{2} \mathrm{O}_{3}$ are $292.7 \mathrm{MPa}$ and $272.8 \mathrm{MPa}$, respectively. Above $900^{\circ} \mathrm{C}$, the flexural strengths of the ceramics decrease to almost $50 \%$ of their values at $25^{\circ} \mathrm{C}$. At $1500^{\circ} \mathrm{C}$, the reduction in the flexural strengths of sapphire and $\mathrm{ZrO}_{2}$, which maintains strengths of around $150 \mathrm{MPa}$, is less than that for the alumina ceramics.

As shown in Figure $4(\mathrm{~b})$, at $25^{\circ} \mathrm{C}$, the flexural moduli of the alumina samples are greater than those of the sapphire and $\mathrm{ZrO}_{2}$ sample. At $900^{\circ} \mathrm{C}$, the flexural moduli of the alumina ceramics and sapphire decrease to approximately $46 \%$ of their value at $25^{\circ} \mathrm{C}$, whereas the flexural modulus of $\mathrm{ZrO}_{2}$ reduces to $25.414 \%$ of its value at $25^{\circ} \mathrm{C}$. At $1200^{\circ} \mathrm{C}$, the flexural modulus of $99 \mathrm{Al}_{2} \mathrm{O}_{3}$ is $12.12 \mathrm{GPa}$, greater than that of $97 \mathrm{Al}_{2} \mathrm{O}_{3}(9.21 \mathrm{GPa})$, sapphire $(9.93 \mathrm{GPa})$, and $\mathrm{ZrO}_{2}$ (6.19 GPa).

As shown in Figure 5(a), the thermal conductivities of these ceramics rapidly decrease as the temperature increases from $25^{\circ} \mathrm{C}$ to $800^{\circ} \mathrm{C}$ and remain stable at temperature above $1000^{\circ} \mathrm{C}$. Although the thermal conductivity of $\mathrm{ZrO}_{2}$ at 


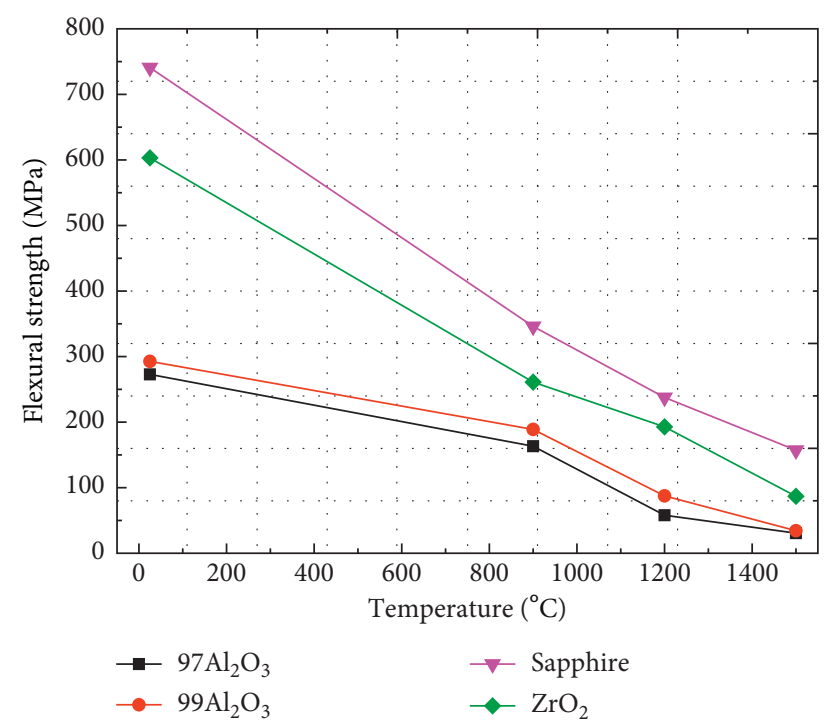

(a)

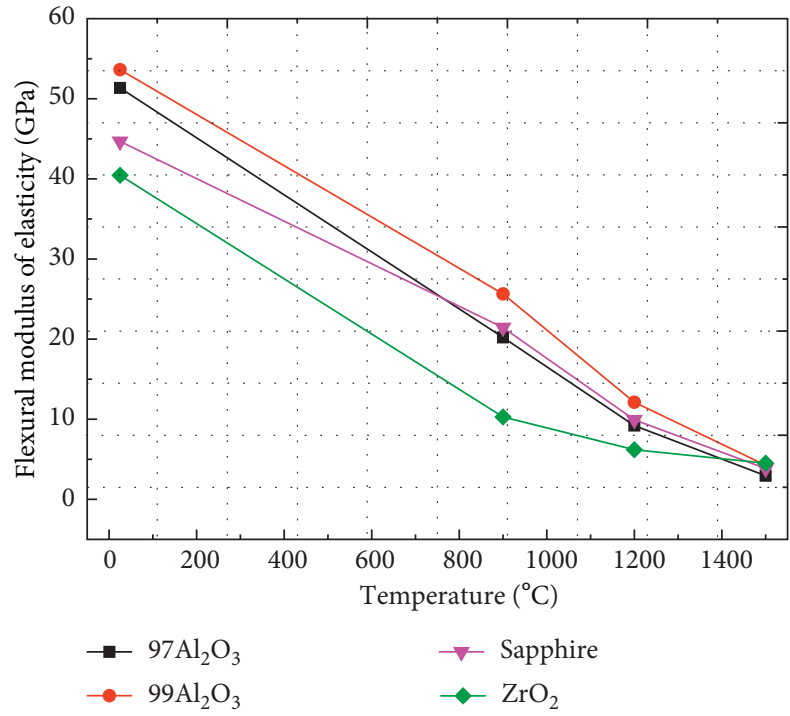

(b)

FIgURe 4: Flexural test result at different temperatures: (a) flexural strengths and (b) flexural moduli.

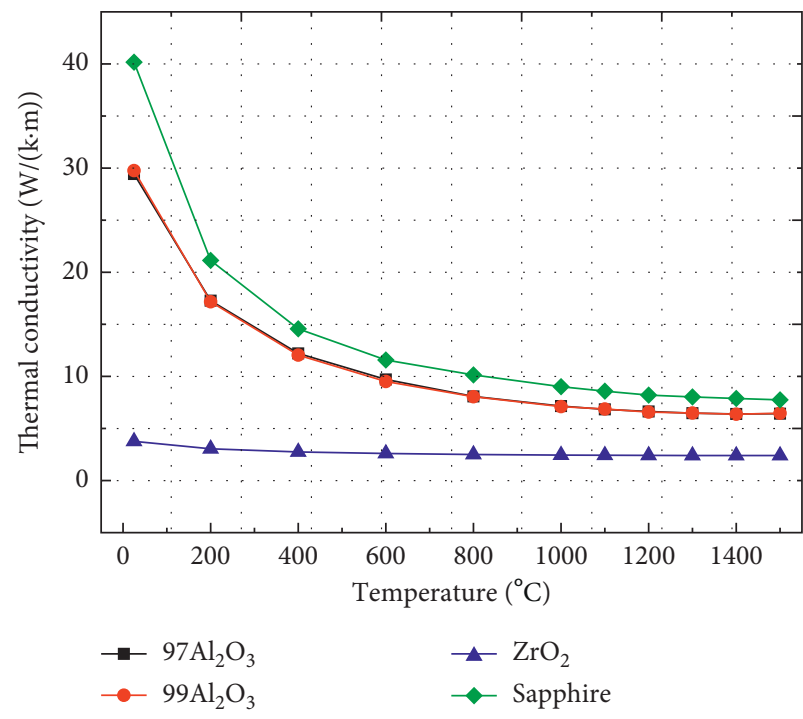

(a)

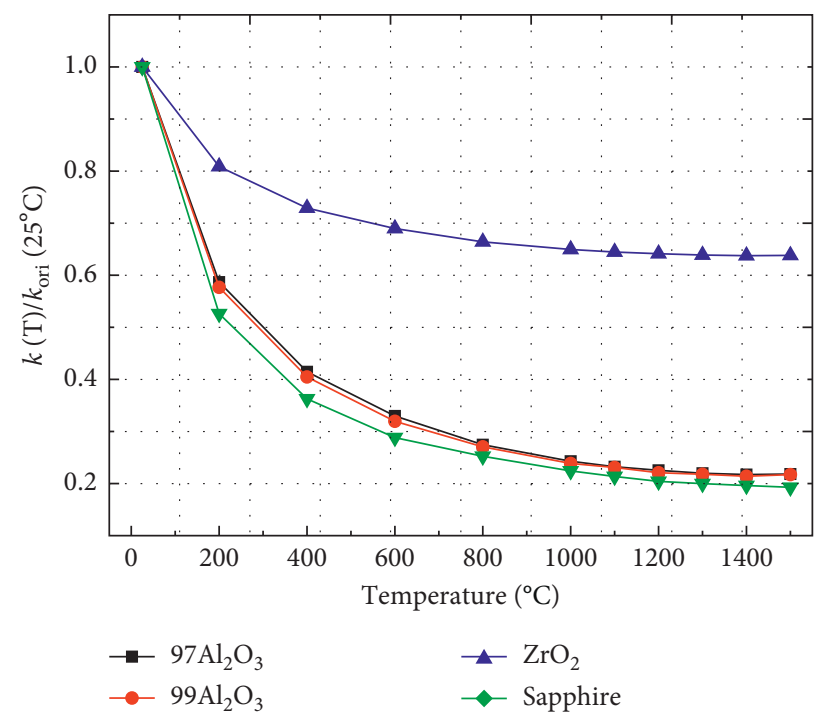

(b)

FIgURE 5: (a) Thermal conductivity change with the temperature. (b) The percentage of the thermal conductivity change with temperature.

$1500^{\circ} \mathrm{C}$ is still over $60 \%$ of its value at $25^{\circ} \mathrm{C}$, it is still significantly lower than the thermal conductivities of the alumina ceramics and sapphire. At all temperatures, sapphire has the highest thermal conductivity among the four ceramics tested.

\section{Conclusion}

In this work, three-point bend testing and transient laser emission were used to determine whether four ceramics are suitable for use as substrate materials for high-temperature pressure sensors; $99 \mathrm{Al}_{2} \mathrm{O}_{3}, 97 \mathrm{Al}_{2} \mathrm{O}_{3}$, sapphire, and $\mathrm{ZrO}_{2}$ were the ceramics investigated. The flexural moduli and the flexural strengths of the alumina ceramics and sapphire make them suitable for use as substrate materials in hightemperature pressure sensors for operation above $1000^{\circ} \mathrm{C}$. Sapphire is suitable for use as a substrate in sensors operating in the environments above $1200^{\circ} \mathrm{C}$. In terms of the thermal conductivity, high-temperature pressure sensors made from sapphire can achieve shorter response times and higher test accuracies than those made from other materials. The thermal conductivity of $\mathrm{ZrO}_{2}$ is too low and will lead to large errors if used as a substrate material for high-temperature pressure sensors. However, this low thermal conductivity renders it suitable for use in thermal insulation. 


\section{Conflicts of Interest}

The authors declare that they have no conflicts of interest.

\section{Authors' Contributions}

All works in relation to this paper have been accomplished by all authors' efforts. The idea and test scheme were proposed by YanJie Guo. The preparation of the test sample was completed by Fei Lu. The experiments of the flexural parameters were completed with the help of Lei Zhang and HeLei Dong. At last, every segment relate to this paper is accomplished under the guidance of QiuLin Tan and JiJun Xiong.

\section{Acknowledgments}

This work was supported by the National Natural Science Foundation of China (Grant nos. 61471324 and 51425505), the Outstanding Young Talents Support Plan of Shanxi province, and the Fund for Shanxi "1331 Project" Key Subject Construction.

\section{References}

[1] M. Narayanaswamy, R. J. Daniel, K. Sumangala, and C. Antony Jeyasehar, "Computer aided modelling and diaphragm design approach for high sensitivity silicon-oninsulator pressure sensors," Measurement, vol. 44, no. 10, pp. 1924-1936, 2011.

[2] S. Li, T. Liang, W. Wang, Y. Hong, T. Zheng, and J. Xiong, "A novel SOI pressure sensor for high temperature application," Journal of Semiconductors, vol. 36, no. 1, p. 014, 2015.

[3] T. H. Lee, S. Bhunia, and M. Mehregany, "Electromechanical computing at $500 \mathrm{C}$ with silicon carbide," Science, vol. 329, no. 5997, pp. 1316-1318, 2010.

[4] D. A. Mills, D. Alexander, G. Subhash, and M. Sheplak, "Development of a sapphire optical pressure sensor for hightemperature applications," in Proceedings of Sensors for Extreme Harsh Environments, International Society for Optics and Photonics, vol. 9113, p. $91130 \mathrm{H}$, Baltimore, MD, United States, 2014.

[5] J. Xu, G. Pickrell, X. Wang, W. Peng, K. Cooper, and A. Wang, "A novel temperature-insensitive optical fiber pressure sensor for harsh environments," IEEE Photonics Technology Letters, vol. 17, no. 4, pp. 870-872, 2005.

[6] A. Binder, G. Bruckner, N. Schobernig, and D. Schmitt, "Wireless surface acoustic wave pressure and temperature sensor with unique identification based on $\mathrm{LiNbO}_{3}$," IEEE Sensors Journal, vol. 13, no. 5, pp. 1801-1805, 2013.

[7] Q. Tan, C. Li, J. Xiong et al., "A high temperature capacitive pressure sensor based on alumina ceramic for in situ measurement at $600^{\circ} \mathrm{C}$," Sensors, vol. 14, no. 2, pp. 2417-2430, 2014.

[8] Q. Tan, T. Wei, X. Chen et al., “Antenna-resonator integrated wireless passive temperature sensor based on low-temperature co-fired ceramic for harsh environment," Sensors and Actuators A: Physical, vol. 236, pp. 299-308, 2015.

[9] H. Zhang, Y. Hong, T. Liang et al., "Phase interrogation used for a wireless passive pressure sensor in an $800^{\circ} \mathrm{C}$ hightemperature environment," Sensors, vol. 15, no. 2, pp. 25482564, 2015.
[10] S. Su, F. Lu, G. Wu et al., "Slot antenna integrated re-entrant resonator based wireless pressure sensor for high-temperature applications," Sensors, vol. 17, no. 9, p. 1963, 2017.

[11] C. Li, Q. Tan, W. Zhang, C. Xue, and J. Xiong, "An embedded passive resonant sensor using frequency diversity technology for high-temperature wireless measurement," IEEE Sensors Journal, vol. 15, no. 2, pp. 1055-1060, 2015.

[12] K. Wei, R. He, X. Cheng, R. Zhang, Y. Pei, and D. Fang, "Fabrication and mechanical properties of lightweight $\mathrm{ZrO}_{2}$ ceramic corrugated core sandwich panels," Materials \& Design, vol. 64, pp. 91-95, 2014.

[13] D. Li, W. Li, R. Wang, and H. Kou, "Influence of thermal shock damage on the flexure strength of alumina ceramic at different temperatures," Materials Letters, vol. 173, pp. 91-94, 2016.

[14] M. Marrelli, C. Maletta, F. Inchingolo, M. Alfano, and M. Tatullo, "Three-point bending tests of zirconia core/veneer ceramics for dental restorations," International Journal of Dentistry, vol. 2013, Article ID 831976, 5 pages, 2013.

[15] L. Yu, Y. Feng, J. Yang, T. Qiu, and L. Pan, "Mechanical and thermal physical properties, and thermal shock behavior of $\left(\mathrm{ZrB}_{2}+\mathrm{SiC}\right)$ reinforced $\mathrm{Zr}_{3}[\mathrm{Al}(\mathrm{Si})]_{4} \mathrm{C}_{6}$ composite prepared by in situ hot-pressing," Journal of Alloys and Compounds, vol. 619, pp. 338-344, 2015.

[16] E. Sánchez-González, J. Meléndez-Martínez, A. Pajares, P. Miranda, F. Guiberteau, and B. R. Lawn, "Application of Hertzian tests to measure stress-strain characteristics of ceramics at elevated temperatures," Journal of the American Ceramic Society, vol. 90, no. 1, pp. 149-153, 2007.

[17] J. Cha, J. Seo, and S. Kim, "Building materials thermal conductivity measurement and correlation with heat flow meter, laser flash analysis and TCi," Journal of Thermal Analysis and Calorimetry, vol. 109, no. 1, pp. 295-300, 2012.

[18] H. Xie, H. Gu, M. Fujii, and X. Zhang, "Short hot wire technique for measuring thermal conductivity and thermal diffusivity of various materials," Measurement Science and Technology, vol. 17, no. 1, pp. 208-214, 2005.

[19] S. Min, J. Blumm, and A. Lindemann, "A new laser flash system for measurement of the thermophysical properties," Thermochimica Acta, vol. 455, no. 1-2, pp. 46-49, 2007.

[20] V. Casalegno, P. Vavassori, M. Valle, M. Ferraris, M. Salvo, and G. Pintsuk, "Measurement of thermal properties of a ceramic/metal joint by laser flash method," Journal of Nuclear Materials, vol. 407, no. 2, pp. 83-87, 2010.

[21] B. K. Jang and Y. Sakka, "Influence of microstructure on the thermophysical properties of sintered SiC ceramics," Journal of Alloys and Compounds, vol. 463, no. 1-2, pp. 493-497, 2008. 


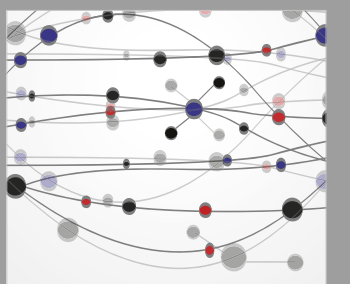

The Scientific World Journal
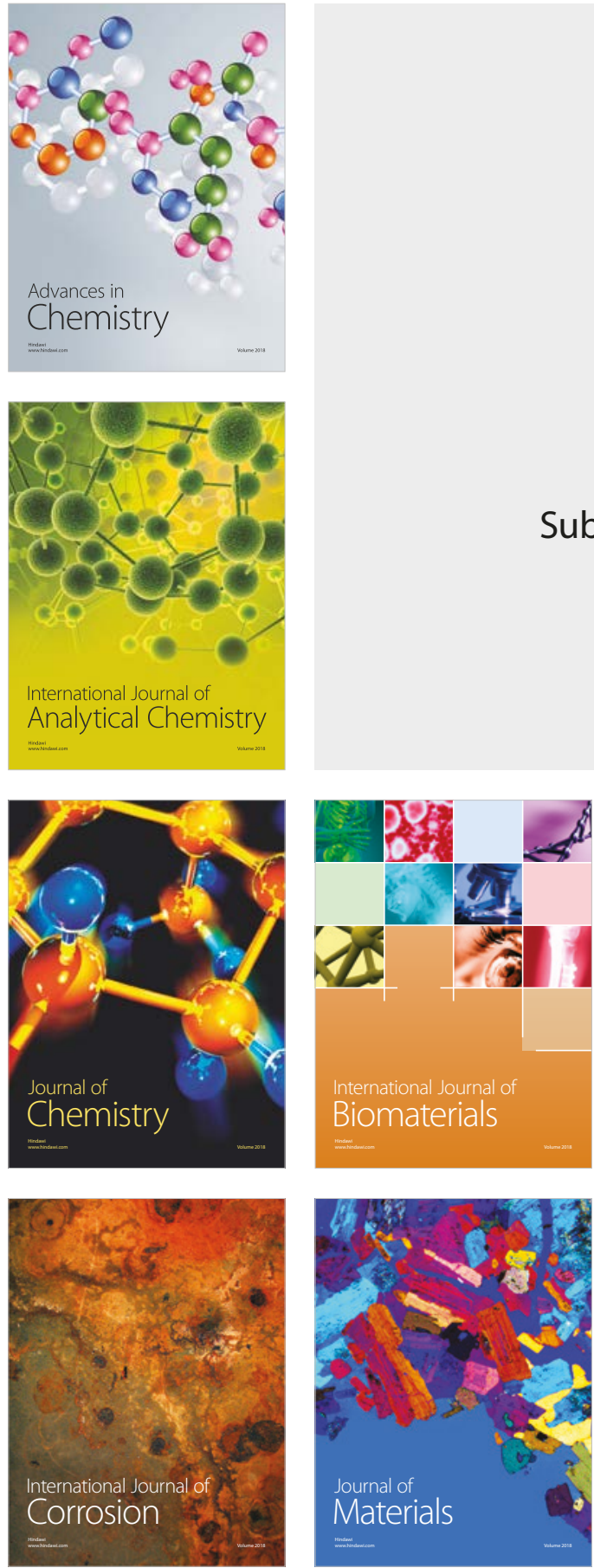

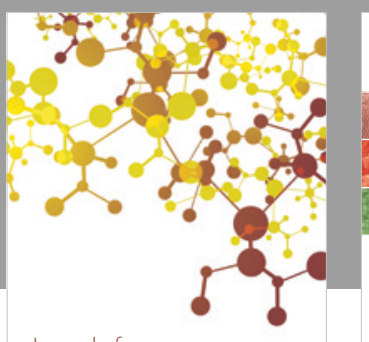

Journal of

Applied Chemistry
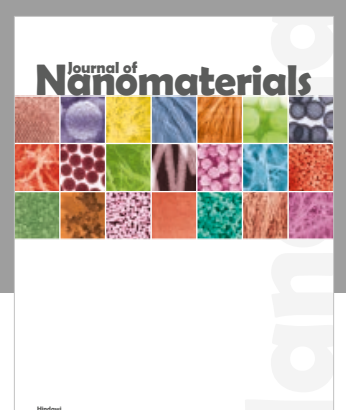

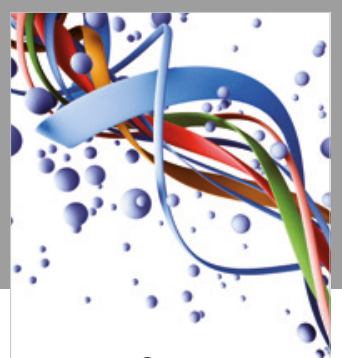

Scientifica

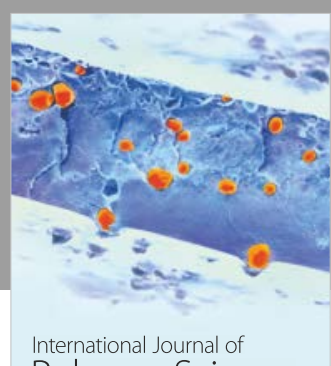

Polymer Science

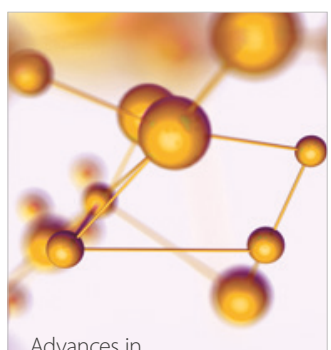

Physical Chemistry
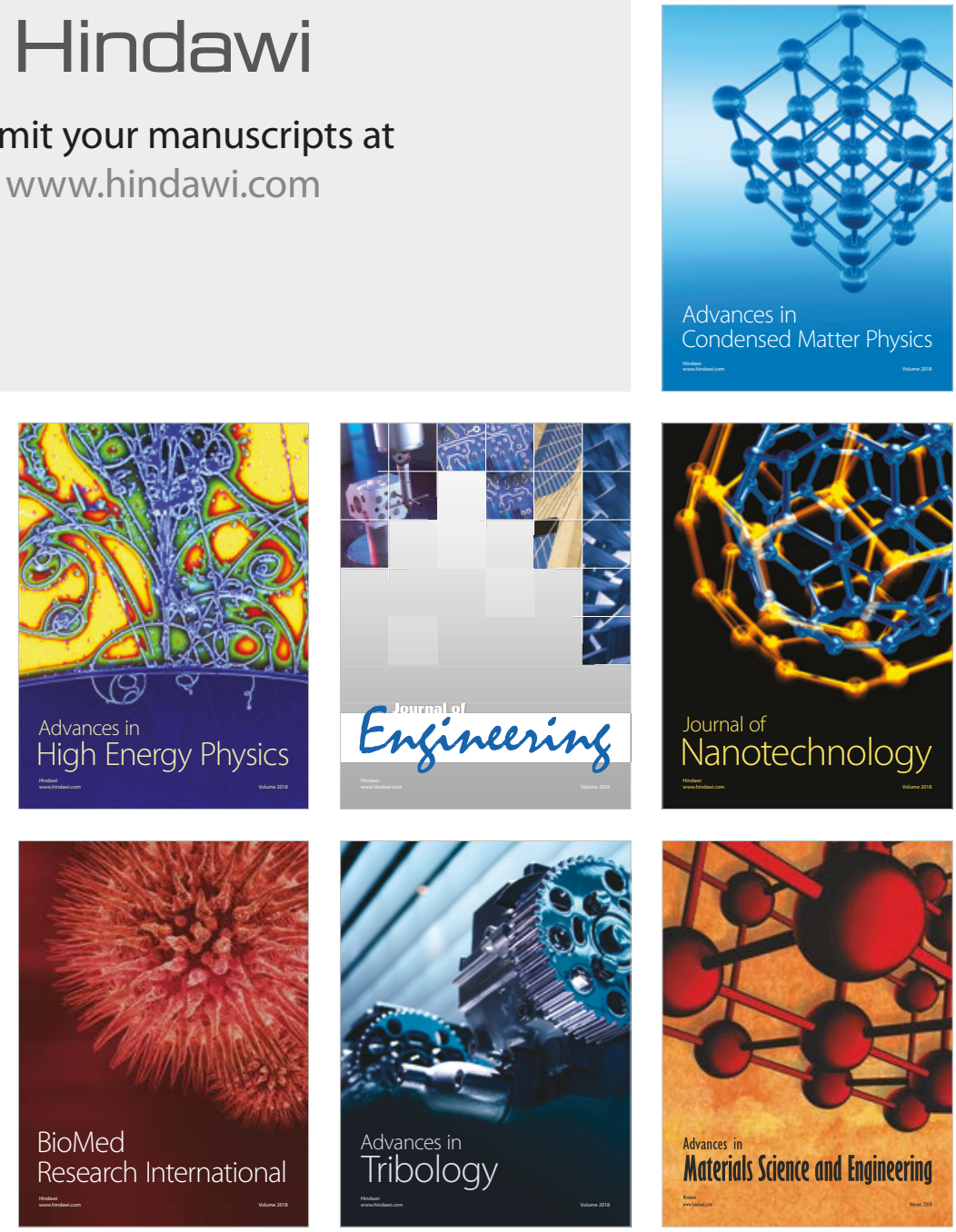